\title{
A Narrative Study on the Image of Filial Piety in Cross-Strait Advertising*
}

\author{
Tingjin Shi \\ Xiamen University Tan Kah Kee College \\ Xiamen, China
}

\begin{abstract}
The cross-strait cultures have their own characteristics. From another perspective, the information conveyed by the advertisements for filial piety culture in Mainland China and Taiwan embodies a common cultural origin and a strong sense of Chinese culture, which has both commercial and social values. The author deeply reads a large amount of literature materials, selects and combines crossstrait representative advertising cases with the theme of filial piety culture in recent years, and explores the filial piety culture rooted in the image narration of cross-strait advertisements and the return of filial piety culture and emotions of China's traditional virtues. It will be helpful to promote cross-strait cultural exchanges and cooperation.
\end{abstract}

Keywords-cross-strait; advertising; image narration; identification; filial piety culture

\section{INTRODUCTION}

Filial piety culture is the core of Chinese traditional culture and the traditional virtue of Chinese nation. Both sides of the Taiwan Straits advocate the traditional Chinese filial piety culture. Since ancient times, there has been the saying that "Filial piety is the foundation of all virtues, and lewdness is the worst of all sins." Liang Shuming once said, "Chinese culture is the culture of filial piety." [1] Zeng Guofan's parental instructions and tradition all emphasize "filial piety" as the foundation. However, in today's society with extremely rich materials and extremely deficient spirits and beliefs, the development of the filial piety culture has experienced unprecedented crises and obstacles. And the essence of the filial piety culture has gradually disappeared. In today's social situation, people pay attention to the materials. And they don't care about moral deficiency. The inclusion of filial piety culture in the creative narrative of commercial and public service advertisements is one of the most effective solutions to the problem of communication. The narrative of advertising images is a spatial narrative method supplemented by images as the main text. It is illustrated with texts and intuitions. It is to facilitate communication and memory. In the information age, image

*"The aesthetic criticism of cross-strait advertising language", a key project of the "Cross-Strait Language Application and Narrative Culture Research Center" of Fujian University Research Innovation Platform (Project Number: LAYY2016004); Application of Cross-Strait Advertising Language and Narrative culture research under the Background of "the Belt and Road Initiative", Fujian Province Social Science Planning Project (Project Number: FJ2017B075). narrative has been widely used in the narration of filial piety culture. The image has become an important "language" of our contemporary culture. Image narrative has become the expression of our contemporary culture. Under this situation, there have also emerged a number of outstanding advertisements on both sides of the Taiwan Strait that use filial piety culture as creative subject matter for the advertising image narration.

\section{THE IDENTITY OF FILIAL PIETY CULTURE FROM THE IMAGE NARRATIVE OF FILIAL PIETY IN CROSS-STRAIT ADVERTISING}

Chen Kongli, an expert on cross-strait relations, pointed out that "both sides of the Taiwan Strait belong to the same Chinese culture, and it can be said that cross-strait culture has the same root. Until now, Chinese culture is still the main culture in Taiwan. And of course, it is also the main culture of mainland China. Both sides of the Taiwan Strait belong to the Chinese culture. The "identity" refers to the similarity. It can be the "same" of the phenomenon and essence. There are many similarities between the cultural representations of the two sides of the Taiwan Strait and even the deep ones. It can be said that the cultures on both sides of the Strait have many commonalities." [2] The commonality of cross-strait cultures creates similarities in the narrative representation of images on both sides of the Taiwan Strait. It is also clearly reflected in the narrative context of the advertising images of the filial piety culture on both sides of the Taiwan Strait. The identification of the filial piety culture on both sides of the Strait is based on common cultural memories and customs, habits, emotions, and ethics on both sides of the Taiwan Strait.

\section{A. Common Cultural Memory}

Jan Assmann proposed the theory of "cultural memory". He thought that "cultural memory" was very rich in content and embodied criss-crossing collective memories such as monuments, ceremonies, festivals, and customs. Both sides of the Taiwan Straits have the same species and share many historical and cultural memories. Under the context of common cultural memory, cross-strait advertisers would make the audience in the mainland and Taiwan can have a good emotional resonance through the advertising media image narrative. 
First of all, there are common language and cultural memories on both sides of the strait. The most basic meaning of filial piety culture is to be good with the parents. In "Erya Shixun", "to be good with the parents is filial piety" [3]. In $\mathrm{Xu}$ Shen's "Shuowen Jiezi" of Eastern Han dynasty, "filial piety culture is to be good with the parents. And the children would wait on and support their parents." [4]. In the Public Service Advertising Competition of Chinese Filial Piety Culture hosted by Xiaogan city, Hubei Province in 2016, the advertisement works "Filial piety is the foundation of all virtues" from Prof. Huang Rongshun of the Chongyou Institute of Technology in Keelung, Taiwan, won the first prize for the print advertisement category. In the narrative of advertising images, 100 characters "善" (kind) were used. And the first character "善" (kind) was written in red as "filial piety", which well highlighted the theme of "goodness and filial piety". When Huang Rongshun received the award, strong filial piety culture in Xiaogan city impressed him. The cross-strait cultural context is the same. And it would keep the writing of Chinese characters. The filial piety culture is reconstructed and extended. And it better explains the crossstrait recognition of the Chinese filial piety culture.

\section{B. Common Customs}

Both sides have the same Spring Festival customs and traditions. In 2010, from one of Taiwan's public bank advertisement "Extraordinary and Ordinary People" Mother's Courage", Taiwan's cultural background with the same confinement as the mainland has become a visual coding format of advertising creativity. This advertisement makes the narration through a film and television commercial image. And it is presented as a miniature movie. A Taiwanese mother named Cai Yingmei, 63 years old, entered a foreign land for the first time. She had language barrier. And then, she arrived in Venezuela after three countries. She took care of her daughter's new production. This is about her story. In the story, she had been arrested when she was at Venezuela's airport due to her "drugs". The so-called "drugs" she carried were actually used for the purpose of cooking chicken soup for her daughter during the confinement period. Chinese herbal medicine shows great maternal love. This advertisement makes cross-strait audiences with the same experience and cultural background has resonance.

In 2015, Taiwan's IKEA's New Year's advertisement "Go Home, Really Good" and the 2018 mainland Vipshop advertisement "Happiness is Together" were closely linked to the filial culture. They interpret the happiness of reunification with parents at home during the Spring Festival. It reflects the same festive customs and Spring Festival culture on both sides of the Taiwan Strait. Through a documentary narrative, Taiwan's IKEA advertisement "Go Home, It's Good" tells a story. The parents hope that their daughters can return home after four daughters were married. And the parents made a reform of indoor landscape during the New Year period. And they wanted to welcome her daughter home. IKEA recorded the surprise when the daughters returned home. It is to remind their sons and daughters to come home and have a good time. Through the image narrative, the mainland Vipshop advertisement "happiness is together" also describes a father's story. During the Spring Festival, his daughter and grandson randomly said that "the signal was bad", "I wanted to go home" and "grandparents do not have a net". The elderly went to the business hall with great effort to set up a network and Wi-Fi. And the grandparents buy expensive TV. The grandchildren could watch clear animation. In order to have more time, the parents would make efforts to make changes. In these two advertisements, parents have been quietly to cater to their children's tastes. However, the rapid development of the information age has brought us a whole new experience while forgetting the elderly parents. The advertisements highlight the headline. And it would lead us to think about the filial piety.

\section{Common Emotion Recognition}

On the basis of the Chinese people's family culture, the mainland and Taiwan have formed a common family member's affection and understanding. They believe that the family is the foundation for peace and life, as well as a harbor for spiritual rest and a support for personal emotions. The affection is always the most deeply rooted creation theme. Viewing from the image narrative of the 2013 CCTV public service advertisement "Daddy Always Remembers You" and the 2014 Taiwan Spring Breeze Advertisement "Auntie's Toilet Paper", all images of filial piety were used to express the filial piety culture on the basis of family emotions. And then, it would achieve precious value.

The CCTV public service advertisement "Daddy Always Remembers You" is one of CCTV's "Caring for the Elderly" series of public service advertisement "Packaging". The narrative content of the Chinese filial piety culture was used as an advertising image to tell about an old father who had Alzheimer's disease. Due to the worsening of his illness, his memory was getting worse and worse, and he could not recognize his son at all. Even the things that he has just done, he can't remember where the refrigerator is, where the washing machine is. However, when he was eating outside, he saw the remaining dumplings in the dish. He still did not forget to "pack" and put them in his pocket and leave them for his son to eat. And his son loved to eat dumplings. In the image narrative, the elderly may not remember anything. However, he could only remember the son's favorite dumplings. It formed stark contrast. The appropriate body language would express the emotion of the characters. The creative prototype of this advertisement, Mr. Yang, once said: "Even if my father can no longer recognize me, I will let him see his beloved son in a blink." It can be seen that this advertisement embodies the filial piety culture thoroughly. And it is intriguing.

Coincidentally, the Taiwanese Spring Breeze advertisement "Aunt's Toilet Paper" described a grandmother who had Alzheimer's disease. When she was little, Grandma wrapped a "gift" in toilet paper every day to make her grandson happy. Surprisingly, he had different surprises every day. I thought that this happiness will never change. However, it seems to have slipped away before I could grasp it. Her grandmother's memory was deteriorating. And she 
can't remember her grandson. However, she still remembered wrapping things in toilet paper to her grandson. No matter what happens, the grandmother's love for the grandchildren will never change. It also stabs the tearful glands of innumerable young people. And at the same time, it inadvertently shows the helplessness of the elderly in modern society. At the same time, as a commercial advertisement, the spring breeze toilet paper has been conveyed with contagious force. The best of the past has never changed.

\section{Common Ethics}

Both the mainland and Taiwan uphold the ethical and moral concepts of family, and pay attention to family responsibilities. In the genealogy of home culture, both sides of the Taiwan Strait recognize that inheritance is only the most traditional concept. The inheritance of morality and good family tradition is the true meaning of "passing down from generation to generation". There is an old saying in China: "Morals passed on for more than ten generations; cultivating and reading was the second; it is followed by poetry and books, family history; and rich family couldn't pass three generations." The moving advertisement of mainland China Spring Festival 2015 "Be Together for Only 24 Hours" and the 2016 Carrefour New Year Advertising in Taiwan "Be Together for Years, Good Homecoming Happiness", and the 2016 Continental Tide Creative Advertising "Mother-in-law and Daughter-in-law" and Taiwan's Shujie Creative Advertising's "Mother-in-law and Daughter-in-law" and "Harem Mother-in-law and Daughterin-law" draw on the ethical norms based on family relations. And it is a "model" of Chinese moral ethical history in thousands of years of history. Image narratives all follow the filial piety culture ethics and moral norms based on family relations.

In the image narrative of the touching advertisement of "Being together for only 24 hours", it would use split-screen techniques and quantified expressions. During the girl's seven-day holiday, it would make a quantitative comparison of the time spent with friends and boyfriends and the real time spent with parents. And then, we would feel how precious to spend time with the parents is during the New Year. I think this is also an important factor in the spread of filial piety culture. Taiwan Carrefour's New Year touching advertisement "Be Together for Years, Good Homecoming Happiness" is also a narrative content of advertising images for people who have spent a long time living in a foreign land. It tells the story of the young people entering their jobs and ignoring their parents. After forming his own family, he was always busy with his own small family. And he would once again ignore old parents. He would always feel the warmth of family. Eating parent's dish is the most euphoric thing. However, it stays in memory, especially for the longevity food that can be eaten only on New Year's Day. The narrative content of advertising images is consistent with the shopping experience of Carrefour, which makes people feel the warmth of home. And it also touches the hearts of many travelers who return home, causing everyone to think about contemporary filial piety culture.
The manifestation of the advertising message in the storyline naturally leads the audience's thinking and emotions. The audience can easily accept the advertisement information and integrate their emotion into the plot. In the advertising image narratives of the mainland's Tide Creative Advertising "mother-in-law and daughter-in-law" and Taiwan's Shujie's creative advertisements "One-second successive development of wife" and "Minus pass of onesecond successive development of wife", the creative themes are all derived from the traditional Chinese filial piety. For example, the twelfth article of "Book of Rites-neize" mentioned: "the wife should service the aunts as the parents". And in "female filial piety- service the aunts", "women should service the aunts, and respect the parents." [5] Both sides of the strait have the same filial piety concept of honoring their parents-in-law. In the image narrative of the mainland's Tide creative advertisement "Mother-in-law and Daughter-in-law", Tide laundry detergent became integrating point for the same interest and peaceful coexistence between the mother and wife, conceiving the meaning of clearing the gap and making love. In the image narratives of Taiwan Shujie's creative advertisement "One-second successive development of wife" and Minus pass of one-second successive development of wife", the product attributes of Shujie kitchen paper "One-second instantaneous absorption" were repeatedly used to resolve the contradictions between mother-in-law and wife-in-law. It shows the intricate relationship between mother-in-law and wife-in-law in daily life. At the same time, it shows the sense of harmony in family relationships. It can be seen that the relationship between mother-in-law and wife-in-law in these creative materials of advertisements is more likely to arouse people's emotional resonance.

\section{The VAlue AND SignificANCE OF THE NARRATIVE IMAGES OF FILIAL PIETY IN CROSS-STRAIT ADVERTISING}

Cross-strait advertising in the filial piety culture is the medium that disseminates the traditional concept of filial piety. Namely, we should service and thank to the parents. Also, we should respect and love the old and the young. And the harmony would be the medium of all things. It would have commercial and social values. Both the mainland and Taiwan have integrated the filial piety culture into the advertising image narrative. It reflects the consensus of the cross-strait solving the lack of effective methods for filial piety culture in the modern society, as well as one of the ways to promote cross-strait deepening of cultural understanding and exchanges. And it is to inherit and develop Chinese traditions. "Chinese filial piety culture has strong cohesiveness that is thicker than water. And filial piety culture has the connotations of worship for ancestors, patronage for loved ones, attachment to native land, and so on. The filial piety has great appeal and affinity for people. It can arouse people's filial piety awareness and evoke people's homesick roots. We should make full use of this reasonable factor in the traditional filial piety that can effectively gather people's minds and integrate manpower, and bring the people of the whole country and the world. And then, they would make contribution to the development of the nation and the progress of the nation. [6] 


\section{A. Commercial and Social Values}

Both sides of the strait regard filial piety culture as the creative theme of advertisement image narrative, which reflects that both sides of the strait attach importance to the excavation of Chinese traditional culture in the aspect of advertisement creative theme. And they would create advertisements with Chinese cultural characteristics. The Buick Auto Advertisement "The inherent happiness" in 2017 and the Taiwan Hebe Treasury Life Advertisement "My Mentally Impaired Father" in 2013, the 2012 China GOME advertisement "Gift to Parents" and the 2012 Taiwan Mitsubishi Automobile advertisement "Road-Daddy's Back" take the filial piety culture as the breakthrough point, and arouse the public's emotion resonance. And then, it would realize the commercial value and the social value which the filial piety culture advertisement spreads and inherits.

In the image narrative of Buick's "The inherent happiness", the three generations of families living together cannot be together because of limited means of transportation, travel, dinner and so on. Buick's automobile advertisement combines the happiness of filial piety culture, the three generations of the whole family who are not absent with the emotional appeals. The Taiwanese Hopewell Treasury Life advertisement, "My Mentally Impaired Father" tells the story of fathers and sons who lived together. After their father suffered from Alzheimer's disease, he did everything he could to give his son the last financial attention. In the final subtitle of the advertisement, "We should share the film for more people to read, and Hebrew Treasury Life would make donation to help more mentally handicapped elderly people." This advertisement fully borrows the emotional appeal while realizing the commercial value. And it also promotes the Chinese traditional filial piety culture. The consumers take the initiative to accept the advertisement information. This would purify and promote the development of advertisement industry.

The mainland China GOME advertisement "Gifts to Parents" tells the story of a mother who is reluctant to replace a disrepair refrigerator for the sake of her child. When the child grows up, they would buy the refrigerator as a gift to give back to the parents. Taiwan's Mitsubishi Auto Advertisement "Road-Daddy's back" takes the narrative theme of thanksgiving parents. The details of our lives that are gradually forgotten as we grow up are still the most precious memories of our parents. Daughters skillfully look at the back of their bike-riding fathers in the car. And the parents will always guide us home. This would arouse our reflections. Combining filial piety culture theme, commercial advertisement would realize commercial value and give consideration to public welfare communication, which is the development trend of modern commercial advertisement.

\section{B. Cross-straits Consensus on Effective Ways to Solve the Lack of Filial Piety Culture in Modern Society}

At present, Chinese traditional filial piety culture is applied to the narrative of advertising images. To spread the traditional culture of filial piety has important social significance. It would promote cross-strait family harmony, and improve cross-strait cultural exchange.

In the narrative of the 2013 CCTV public service advertisement "Dad's Lies", the elderly father concealed mother's illness on the telephone and took care of her alone. And the daughter wouldn't worry about them. He is very lonely. However, he says that he has many friends. At the end of the advertisement, there is a sobering question, "Can you understand the father's lies?" It also touched the hearts of many children working outside the home. And it advocates that the children should service parents. And "we can't express love too late. We should go home." In 2013, the author designed the public service advertisement "Back Shadow", which won the award in the 10th Design Capital (Shenzhen, China) Public Service Advertising Competition. And the author made use of the light and shadow to make the design effect of visual misvision. The back shadow of the lonely old man in the image gradually is far away, resulting in the life regret that "the tree craves calm but the wind will not abate, children would like to support but parents can't wait". It hopes to arouse the love to the empty nest old man. In "The Analects of Confucius-Liren", "If the parents are live, we had better not go far away. Or, we must travel with a plan." In response, in September 2012, the Taiwan Tourism Association launched a huge outdoor LED filial piety advertisement "Filial Parents - Taiwan Tour" in Xiushui Street, Beijing Railway Station Square, inviting mainland youth to take their parents to Taiwan. It is in line with the 20th filial piety in the new "24 filial piety" in mainland China to take their parents have a trip. The filial piety culture advertisement has become one of the ways to deepen crossstrait cultural understanding and exchanges.

\section{Rethinking on Inheriting and Developing Chinese Traditional Culture}

In February 2018, the People's Daily New Media launched a large-scale public-interest network interaction with a number of online media, including the most widely publicized advertisement "Mother's Hand", which made people feel most shocked. An image of General Secretary Xi Jinping walking with his mother shocked people. And the dubbing is intonation of the General Secretary of the "Travelers's Song". It tortures each Chinese people's heart. Have you "lead mother's hand" during this year's Spring Festival? "Travelers's Song" was pulled out from the general secretary's mouth and stirred up the resonance of countless people. In "Shi-Xiaoya-Lue", "The father gave birth to me, and the mother reared me. They would touch me and love me. Also, they would educate me and take care of me. They would hold me. Now we want to support the parents. However, the god has no reason to make disaster." Filial piety is the return of parental gratitude and the inheritance of Chinese excellent traditional culture. With the good family style of tens of thousands of families, it can support the good atmosphere of the whole society. And it is the basic point of national development, national progress and social harmony. According to statistics, more than 680 million people participated in "holding mother's hand". They have the warmest memory of the Spring Festival. 
With the change and development of social environment, the form of filial piety is constantly changing. The essence of filial piety has never changed. The filial piety is still the core culture of the traditional virtues of the Chinese nation. Compared with the traditional "24 filial piety", the new "24 filial piety" is more innovative and closely related to the modern social life. It emphasizes the psychological concern for the elderly. For example, the fifth filial piety does not forget to call the parents every week. It has the distinctive characteristics of the times and leads people go out of the mistaken idea of filial piety and promotes the new filial piety culture.

The warm public service advertisement "Grandma's Lantern" in 2017 recounted the warm and touching story of grandparents taking care of their grandchildren as the parents worked outside the home. After growing up, he found that the warmest time of his life was the time he spent with grandma. This is similar to the mainland life background. Through the advertising image narrative dissemination, everyone pays attention to filial piety culture. They would respect relatives. Just as "Mencius-Wanzhang" said, "filial son would give the greatest respect for relatives" [7]. The 2017 JW Thomson Creative Public Interest Advertisement "Please give us the time to sing" is similar to the Taiwanese Public Interest Advertisement "Grandma's Lantern" in the narrative of more than 60 million left-behind children living with their grandparents in the remote countryside of China. Some of these households are too poor to pay for telephone calls or are unable to communicate with their parents because of poor communication equipment. The advertisement aims to raise consumers' awareness of the "echo plan" and achieve a desire to communicate with parents for left-behind children through the use of Tennent's mobile phone.

The filial piety culture in the narrative communication of advertising images on both sides of the strait realizes the commercial value and social value and plays an active role in the harmony of family and social stability. In contemporary society, advertising image narrative communication is one of the innovative forms of inheriting the traditional filial piety culture. And it is an effective way to solve the crisis and obstruction of filial piety culture. Reconstruction of the new culture of filial piety is of great social value and practical significance for the development of national culture and the construction of spiritual civilization service in modern society.

\section{CONCLUSION}

There is an intriguing story behind each advertisement in this article. These stories annotate the connotation and inheritance of filial piety culture with image narrative language, and deduce the same root of filial piety culture on both sides of the strait. Whether it is the public service advertisement that spreads the Chinese traditional filial piety culture or the commercial advertisement that seeks the best balance between commercial value and public service value, it all seeks a new path for inheriting the traditional filial piety culture. The cross-strait perspective of this paper is helpful to promote the common feelings of compatriots on both sides of the strait. It would meet the requirements of the times, and construct the cross-strait common values and public morality of the excellent traditional culture.

\section{REFERENCES}

[1] Liang Shuming. "The Essentials of Chinese Culture", Shanghai People's Publishing House, 2nd edition, June 2011, p. 278. 梁漱溟: 《中国文化要义》，上海人民出版社 2011 年 6 月第 2 版，第 278 页。

[2] Chen Kongli. "The Essential Differences between the Cultures on Both Sides of the Taiwan Strait", Taiwan Research Collection, Issue 4 2013. 陈孔立: 《两岸文化的本质差异》, 《台湾研究集刊》2013 年第 4 期

[3] [Eastern Jin Dynasty] Guo Pu. "Er Ya", Zhonghua Book Company, 1985 edition, p. 32.(东晋) 郭璞注: 《尔雅》，中华书局 1985 年 版，第 32 页

[4] [Han] Xu Shen. "Shuowen Jiezi", Tianjin Classical Publishing House, June 1991, Vol.8 (汉) 许慎: 《说文解字》, 天津市古籍出版社 1991 年 6 月版, 卷八。

[5] Cui Gaowei. "Book of Rites", Liaoning Education Press, March 2000, p. 93. 崔高维校点: 《礼记》, 辽宁教育出版社 2000 年 3 月版, 第 93 页

[6] Chen Xiaoming. "The Contemporary Social Value Theory of Chinese Traditional Filial Piety Culture", "Exploration" Issue 3, 2008. 陈晓 明: 《中国传统孝文化的当代社会价值论》, 《求索》2008 年 第 3 期

[7] [Han] Han Ying. The Collection of Han Poetry, May 2009, Volume 9 (汉) 韩婴：《韩诗外传集释》2009年 5 月版，卷九 